Review

\title{
Essences in Metabolic Engineering of Lignan Biosynthesis
}

\section{Honoo Satake ${ }^{1, *}$, Tomotsugu Koyama ${ }^{1}$, Sedigheh Esmaeilzadeh Bahabadi ${ }^{2}$, Erika Matsumoto ${ }^{1}$, Eiichiro Ono ${ }^{3}$ and Jun Murata ${ }^{1}$}

1 Bioorganic Research Institute, Suntory Foundation for Life Sciences, Osaka 618-8503, Japan; E-Mails: koyama@sunbor.or.jp (T.K.); matsumoto@sunbor.or.jp (E.M.); murata-j@sunbor.or.jp (J.M.)

2 Department of Biology, Faculty of Basic Sciences, University of Zabol, Zabol, Iran; E-Mail: shirin_esm@yahoo.com

3 Research Institute, Suntory Global Innovation Center (SIC) Ltd., Osaka 618-8503, Japan; E-Mail: eiichiro_ono@suntory.co.jp

* Author to whom correspondence should be addressed; E-Mail: satake@sunbor.or.jp; Tel.: +81-75-962-6092; Fax: +81-75-962-2115.

Acedemic Editor: Dirk Steinhauser

Received: 26 February 2015 / Accepted: 27 April 2015 / Published: 4 May 2015

\begin{abstract}
Lignans are structurally and functionally diverse phytochemicals biosynthesized in diverse plant species and have received wide attentions as leading compounds of novel drugs for tumor treatment and healthy diets to reduce of the risks of lifestyle-related non-communicable diseases. However, the lineage-specific distribution and the low-amount of production in natural plants, some of which are endangered species, hinder the efficient and stable production of beneficial lignans. Accordingly, the development of new procedures for lignan production is of keen interest. Recent marked advances in the molecular and functional characterization of lignan biosynthetic enzymes and endogenous and exogenous factors for lignan biosynthesis have suggested new methods for the metabolic engineering of lignan biosynthesis cascades leading to the efficient, sustainable, and stable lignan production in plants, including plant cell/organ cultures. Optimization of light conditions, utilization of a wide range of elicitor treatments, and construction of transiently gene-transfected or transgenic lignan-biosynthesizing plants are mainly being attempted. This review will present the basic and latest knowledge regarding metabolic engineering of lignans based on their biosynthetic pathways and biological activities, and the perspectives in lignan production via metabolic engineering.
\end{abstract}


Keywords: lignan; biosynthesis; metabolic engineering; elicitor; transgenic plant

\section{Introduction}

A tremendous increase in the number of elderly individuals has caused a rapid escalation of medical care expenses. This may eventually lead to a serious disruption in essential medical care systems and national financial burdens. To address these issues, extensive efforts are therefore underway to increase the healthy life expectancy, prevent lifestyle-related diseases, and make progress in medical treatments. Consequently, the consistent and appropriate intake of dietary supplements and the efficient development of clinical drugs are the most promising and effective ways to achieve these goals.

Dietary supplements and drug compounds are largely derived from specialized metabolites, previously called secondary metabolites of plants, including alkaloids, flavonoids, isoflavonoids, and lignans. As depicted in Figure 1A, lignans are naturally occurring phenylpropanoid dimers (C6-C3 unit; e.g., coniferyl alcohol), in which the phenylpropane units are linked by the central carbons of the side chains. These specialized metabolites are classified into eight groups based on their structural patterns, including their carbon skeletons; the way in which oxygen is incorporated into the skeletons; and the cyclization pattern: furofuran, furan, dibenzylbutane, dibenzylbutyrolactone, aryltetralin, arylnaphthalene, dibenzocyclooctadiene, and dibenzylbutyrolactol [1,2]. Unfortunately, the amounts of lignans and their precursor molecules in model plants such as Arabidopsis thaliana and Nicotiana tabacum are quite low. Moreover, plant sources of lignans are frequently limited because of the high cost of plant hunting and collection, poor cultivation systems, long growth phase, and the low lignan content [1-12]. For instance, sesamin, a multifunctional sesame seed lignan, is extracted from sesame seed oil, the most abundant source of this compound. Nevertheless, sesamin at most constitutes $0.4 \%-0.6 \%(\mathrm{w} / \mathrm{w})$ of sesame seed oil. Moreover, sesame seeds are cultivated only once per year, limiting the ability to obtain large amounts of this compound. Likewise, podophyllotoxin (PTOX), a lignan that is a precursor of semi-synthetic antitumor drugs, is isolated from the roots and rhizomes of Podophyllum hexandrum, which is distributed in very limited regions, and is now endangered due to overharvesting and environmental disruption [13]. In addition, the complicated chemical structures of PTOX and the related compounds (Figure 1A) make stereoselective organic synthesis impractical and costly for producing large supplies of these compounds and the resulting high cost [1-12]. These drawbacks indicate the requirement for efficient, stable and sustainable production systems for producing lignans.

There has been a growing body of reports on the molecular characterization of the enzymes involved in the biosynthesis of lignans, lignan-production using lignan-rich plants or cultured plant cells, including Linum, Forsythia, and Podophyllum species [14-18], and the physiological analyses of their biological activities in mammals. These findings have allowed us to attempt the metabolic engineering of lignan biosynthesis in Linum, Forsythia, and Podophyllum species. This review article will provide current knowledge of lignan production via metabolic engineering and perspectives in the development of metabolic engineering-based lignan production. 
A
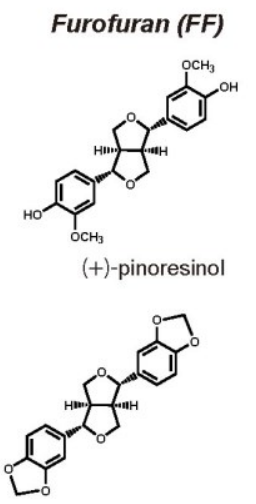

$(+)$-sesamin
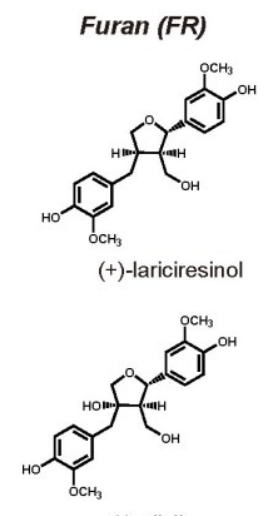

(-)-olivil

Dibenzylbutyrolactone (DBL)

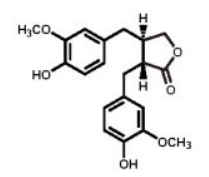

(-)-mataireisnol

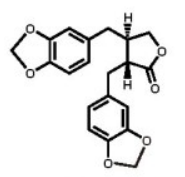

(-)-hinokinin

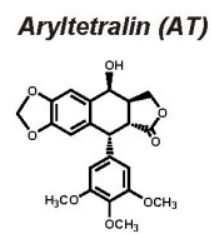

(-)-podophyllotoxin

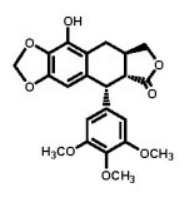

(-)- $\beta$-peltatin

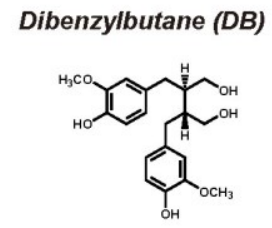

(-)-secoisolariciresinol

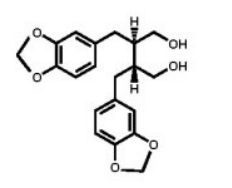

(-)-dihydrocubebin
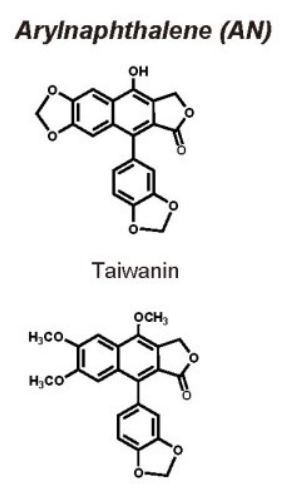

Justicidin A
Dibenzylbutyrolactol (DBLL)

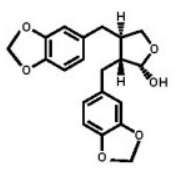

(-)-cubebin

Dibenzocyclooctadien (DCO)

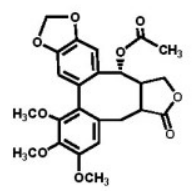

(-)-steganacin

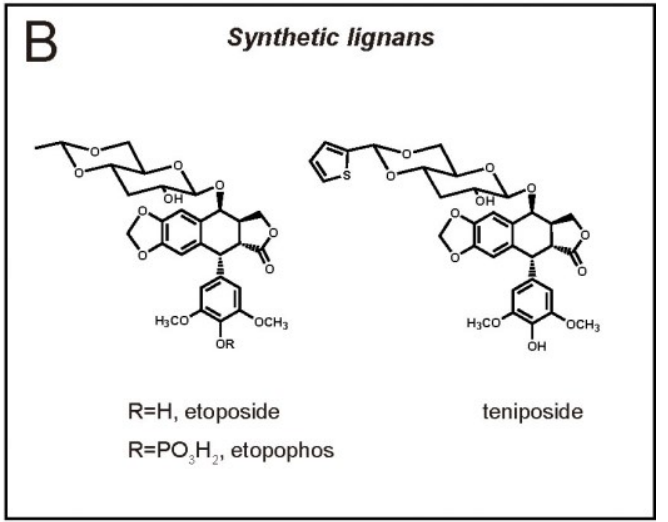

Figure 1. Chemical Structures of Typical Lignans in (A) Dietary and Medicinal Sources and (B) Synthetic Podophyllotoxin Derivatives.

\section{Lignan Biological Activity on Mammals}

Although lignans exhibit a wide variety of bioactivities on plants, insects, and mammals [12,19-24], they are of especial interest due to the unique antitumor-associated activities and reduction of lifestyle-related diseases. Lignans and their glycosides, including pinoresiniol, sesamin, lariciresinol, secoisolariciresinol, and matairesinol, are metabolized by intestinal microflora to yield enterodiol and enterolactone, which are well known as enterolignans or mammalian lignans [25-27]. These metabolized lignans elicited their modest estrogen-like activity in mammals. For example, enterolignans bind to the mammalian estrogen receptors (ER), ER $\alpha$ or ER $\beta$, which are key regulatory factors in the sexual maturation of genital organs [28,29]. Consequently, enterolignans, combined with other intestinal flora-generating metabolites of isoflavones and coumestans, are also called phytoestrogens.

It should also be noteworthy that low concentration of intact lignans have been detected in the sera of mammals fed with lignan-rich diets, suggesting that non-metabolized lignans are taken up by the mammalian digestive system and manifest ER-independent activities in vivo and in vitro, including tumor growth suppression, angiogenesis inhibition, and reduction of diabetes [6,30-35].

Lignans have also been shown to exhibit positive effects on other lifestyle-related diseases. Administration of flaxseed lignan complexes improved hyperglycemia and markers of type II diabetes 
in elderly patients and various animal models [36,37]. In particular, secoisolariciresinol diglucosides (SDG), secoisolariciresinol, enterodiol and enterolactone inhibited pancreatic $\alpha$-amidase activity in a non-competitive manner [38]. Sesamin and its metabolites exhibited anti-hypertensive activities [39-41]. The anti-oxidative propensity of sesamin is also likely to be involved in protecting the liver from oxidation by alcohols, lipids, and oxygen radicals [39,42-44]. In human intestinal Caco 2 cells, pinoresinol decreased the production of inflammatory factors, such as interleukin-6 and prostaglandin E2, following the down-regulation of Cox-2, an inducible prostaglandin synthase that is responsible for the synthesis of prostaglandin $\mathrm{H}$, a precursor of any other prostaglandins [30]. In contrast, matairesinol increased levels of prostaglandin E2 [30]. These findings proved that pinoresinol and matairesinol have opposite effects in these cells [30].

Of the most prominent epidemiological significance is that intake of lignan-rich foods, such as flaxseeds and sesame seeds, has been found to reduce breast cancer risk and improve the breast cancer-specific survival of postmenopausal women [34,45-50]. Moreover, serum enterolactone levels were positively and significantly correlated with improved prognosis in postmenopausal women with breast cancer [51]. These epidemiological findings suggest the unique suppressive activity of lignans against breast cancer risks in elderly women.

Oral lariciresinol was found to suppress tumor growth and angiogenesis in nude mice implanted with human MCF-7 breast cancer via the induction of apoptosis and the up-regulation of ER $\beta$ expression [35]. SDG potently inhibited cell proliferation and induced the apoptosis of breast cancer cells via the down-regulation of ER- and growth factor-mediated gene expression in athymic mice [52]. Sesamin reduced signaling downstream of mitogen-activated protein kinase [53], and is likely to more potently reduce breast tumor growth, compared to SDG [53]. Consistent with the abundance of various lignans in several foods including flax or sesame seeds and oils, these pharmacological effects suggest that lignans are promising dietary compounds for the prevention of breast cancer. PTOX and its structurally related natural compounds exhibit the suppressive activity on mitotic spindle assembly by binding to tubulin, resulting in cell cycle arrest at metaphase [18]. The PTOX semi-synthetic derivatives, etoposide, teniposide, and etopophos (Figure 1B), are clinically utilized to treat certain types of cancers, including testicular/small-cell lung cancer, acute leukemia, Hodgkin's and non-Hodgkin's lymphoma [53,54]. These PTOX-derived anti-tumor drugs induce apoptosis of tumor cells by binding to topoisimease II, a key enzyme for cell division [53,54]. In addition, other new PTOX derivatives, including GP-11, NK-611, TOP-53, GL-331, and NPF, are undergoing phase I or II clinical trials as novel cancer drugs [54]. Combined with the difficulty in efficient chemical synthesis of PTOX due to its complicated structure, these findings highlight the importance of PTOX as a natural seed material for the production of various anti-cancer drugs.

In combination, these epidemiological and physiological studies demonstrate that lignans exert diverse, but specific, beneficial effects as dietary compounds or medicinal agents for the prevention of lifestyle-related diseases, such as cancer and diabetes of note, respective lignans exhibit both similar and differential bioactivities in mammals, leading to requirements for the efficient and specific production of these compounds. 


\section{Lignan Biosynthesis Pathways}

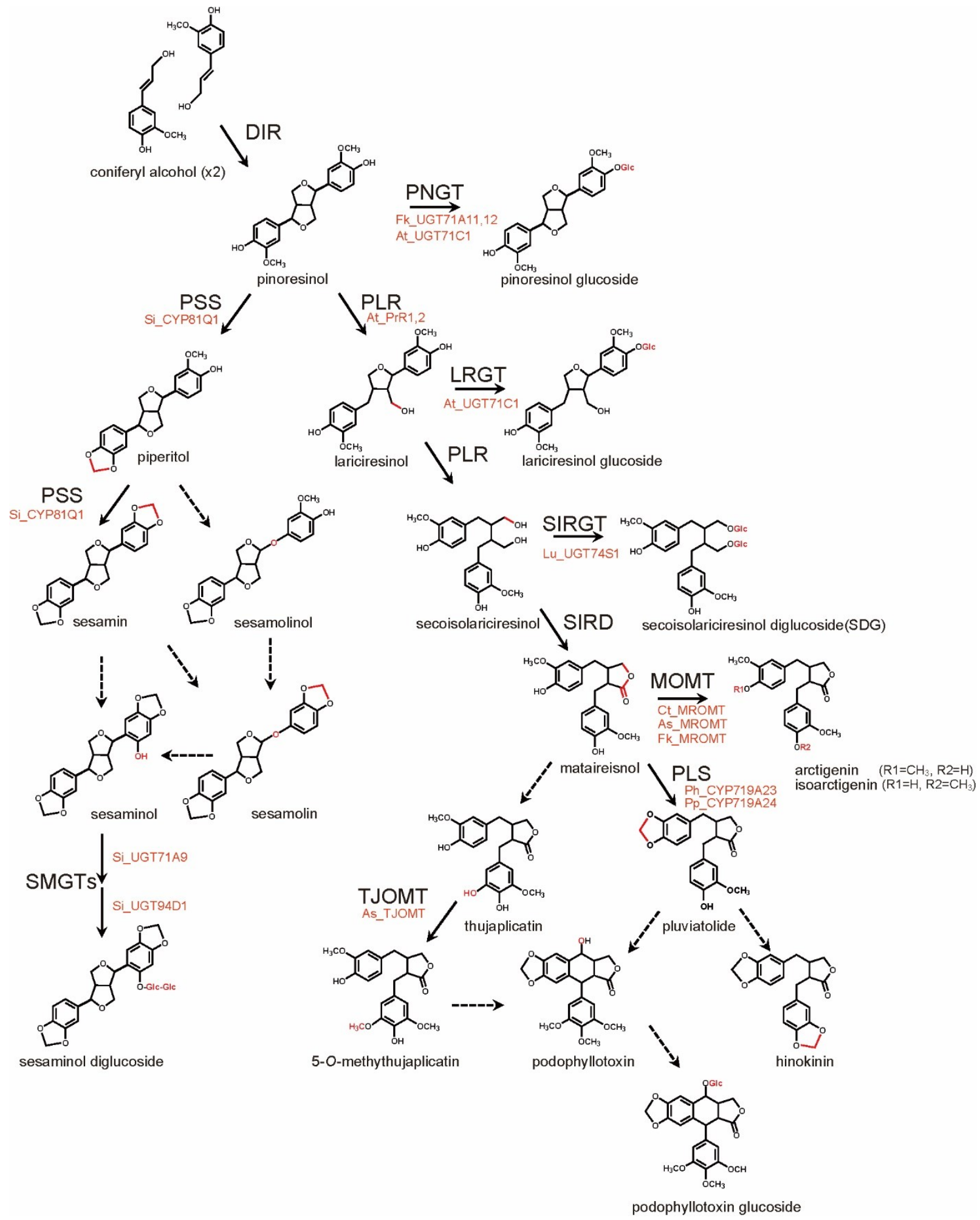

Figure 2. Biosynthesis Pathways of Major Lignans. Chemical Conversions at Each Step are Indicated in Red. Solid and Broken Lines Represent Identified and Unidentified Enzyme-catalyzed Reactions, Respectively.

To date, two major lignan biosynthesis pathways have been identified. Both of the pathways originate from the coupling of achiral $E$-coniferyl alcohol, leading to the generation of pinoresinol, a basal lignan 
(Figure 2). Although a pinoresinol synthase has yet to be identifed, a dirigent protein (DIR) was shown to participate in the stereo-specific dimerization of $E$-coniferyl alcohol [55]. In diverse plant species including Forsythia, Linum, and Podophyllum, pinoresinol is stepwisely reduced to lariciresinol and then secoisolariciresinol by pinoresinol-lariciresinol reductase (PLR), a member of the pinoresinollariciresinol/isoflavone/phenylcoumaran benzylic ether reductase (PIP) family [55-61]. PLR converts pinoresinol to secoisolariciresinol via lariciresinol (Figure 2). Pinoresinol also undergoes glucosylation by UGT71A18, a UDP-glucose-dependent glucosyltranferase [62]. Such glycosylation is highly likely to suppress the chemical reactivity of a phenolic hydroxyl group of pinoresinol and to potentiate high water solubility of pinoresinol aglycone, resulting in large and stable amounts of pinoresinol $[1,2,11,12]$. Indeed, approximately $90 \%$ of pinoresinol is accumulated in its glucosylated form in Forsythia spp. [63,64]. PLR-catalyzed metabolism and UGT71A18-directed glucosylation are reciprocally competitive pathways (Figure 2), given that both of them share pinoresinol as a substrate. Intriguingly, $P L R$ shows opposite seasonal alteration in gene expression against UGT71A18; in Forsythia leaves in Japan, PLR gene is intensely expressed from April to August but poorly from September to November, whereas gene expression of UGT71A18 is observed at high level from September to November, but at faint or no level from April to August, at least, in Japan [64]. These findings indicate that PLR and UGT71A18 participate in the competitive regulation of lignan biosynthesis via pinoresinol metabolism. In A. thaliana, AtPrR1 and 2 are only responsible for the reduction of pinoresinol to lariciresinol [60], and lariciresinol and pinoresinol are glucosylated by another novel UDP-glucose-dependent glucosyltranferase, UGT71C1 [65].

Secoisolariciresinol, like pinoresinol and lariciresinol, undergoes two metabolic pathways (Figure 2). First, Secoisolariciresinol is converted into matairesinol by secoisolariciresinol dehydrogenase (SIRD) [66]. Second, a novel UDP-glucose-dependent glucosyltranferase in Linum, UGT74S1, generates secoisolariciresinol monoglucoside and SDG [67]. Matairesinol is metabolized to arctigenin (Figure 2) by matairesinol $O$-methytransferase (MOMT) via methylation of a phenolic hydroxyl group in various plants including F. koreana, Carthamus tinctorius, and Anthriscus sylvestris [68,69]. Additionally, $70 \%-90 \%$ of matairesinol is glucosylated throughout the year in the Forsythia leaves [64], although no matairesinol-glucosylating enzymes have been identified. In Linum, Anthriscus, and Podophyllum plants, matairesinol is also converted into hinokinin, yatein, or PTOX via multiple biosynthetic pathways, although all of the relevant enzymes have not yet been identified [1,2,55]. In A. sylvestris, AsTJOMT exclusively methylates the 5-hydroxyl group of thujaplicatin, an intermediate of PTOX [70]. The homologous enzymes, CYP719A23 (from P. hexandrum) and CYP719A24 (from P. peltatum) participate in the conversion of matairesinol into pluviatolide, a more downstream intermediate of PTOX (Figure 2), via methylenedioxy bridge formation [71].

PLR and the downstream biosynthetic enzymes are absent in Sesamum plants [1,2,12,55,72-74]. Instead, pinoresinol is metabolized into piperitol, followed by further conversion into (+)-sesamin by a cytochrome P450 family enzyme, CYP81Q1, which is responsible for via formation of two methylenedioxy bridges [75]. The CYP81Q1 gene is expressed almost exclusively in sesame seeds, which is compatible with sesamin production at the highest level in sesame seeds [75]. Sesamin is anticipated to be further metabolized into sesaminol and sesamolin (Figure 2), but the underlying molecular mechanisms have yet to be elucidated [3,55]. Sesaminol is glucosylated at its 2-hydroxyl group by the homologous enzymes UGT71A8 (S. radiatum), 9 (S. indicium), and 10 (S. alatum). 
Moreover, the resultant sesaminol 2-O-monoglucoside is further glucosylated by UGT94D1, which is specific to the glucosylation of sesaminol 2-O-monoglucoside at 6-position of the conjugated glucose [76].

A number of key lignan biosynthetic enzymes remain to be identified. Over the past few years, however, the genomes or transcriptomes of lignan-rich plants including Linum [77-79], Sesamum [72-74], and Podophyllum [71,80,81] have been documented, followed by in silico detection of functional genes. Particularly, Next-generation sequencing (NGS) is a promising approach for the molecular characterization of lignan biosynthetic enzymes; indeed, CYP719A23 and its homolog were identified by NGS-based transcriptome [71]. These findings are expected to remarkably enhance the molecular and functional characterization of lignan biosynthetic enzymes. In addition, it is suggested that a Podophyllum endophyte may produce PTOX [82]. NGS analyses of the genome, metagenome, and transcriptome of Podophyllum and its endophytes are expected to provide crucial clues to understand the PTOX biosynthesis pathways.

\section{Metabolic Engineering of Lignan Biosynthesis}

To date, cell and organ cultures have been employed for metabolic engineering of lignan biosynthesis. Furthermore, a growing body of studies has revealed that lignan biosynthesis is altered by genetic modification, light, and elicitors. This section presents an overview and discussion of recent progress in typical lignan metabolic engineering using plants, plant cells and organ cultures.

\subsection{Gene Transfection or Silencing}

Stable or transient transfection or gene silencing of a lignan biosynthetic enzyme gene is expected to directly alter the lignin production cascades in host plants, organs, and cells, following the development of methods for gene transfection into hosts of interest.

Forsythia is a perennial plant commonly known as the golden bell flower, and is used for a variety of Chinese medicines and health diets $[1,2,5,7,12,55]$. As shown in Figure 2, Forsythia biosynthesizes pinoresinol, phillygenin, secoisolariciresinol, matairesinol, and arctigenin, with $>90 \%$ of pinoresinol, $>80 \%$ of matairesiol, and $40 \%-80 \%$ of arctigenin accumulated in glucosylated forms $[1,2,63,64,83]$. Identification of these lignans and the relevant biosynthetic enzymes suggests the potential of Forsythia as a platform for lignan production. Although efficient methods for the generation of transgenic Forsythia species have not yet been established [84], the metabolic engineering of Forsythia culture cells was originally reported. Forsythia suspension cells stably transfected with a PLR-RNA interference (RNAi) sequence (PLRRNAi) showed complete loss of matairesinol and an approximately 20 -fold increase in total pinoresinol (pinoresinol aglycone and glucoside), compared with the wildtype cells [63]. Furthermore, Forsythia transgenic cells, CPi-Fk, which are stably double-transfected with PLR-RNAi and the sesaminproducing enzyme, CYP81Q1 (Figure 2), produced sesamin $(0.01 \mathrm{mg} / \mathrm{g}$ dry weight of the cell [DW]) (Figure 3), although sesamin is not biosynthesized in native Forsythia [63]. This is the first success in lignan metabolic engineering leading to an exogenous lignan using transgenic plant cells. In addition, the RNAi-based suppression of UGT71A18 (encoding a pinoresinol-glucosylating enzyme) may lead to the dramatic improvement of sesamin production in CPi-Fk cells, given that pinoresinol glucoside cannot be utilized by CYP81Q1 as a substrate [75], and 90\% of pinoresinol is glucosylated in Forsythia cells $[1,2,63,64,83]$. Thus, the Forsythia cell culture system is an efficient and promising platform for producing both endogenous and exogenous lignans by transgenic metabolic engineering. 


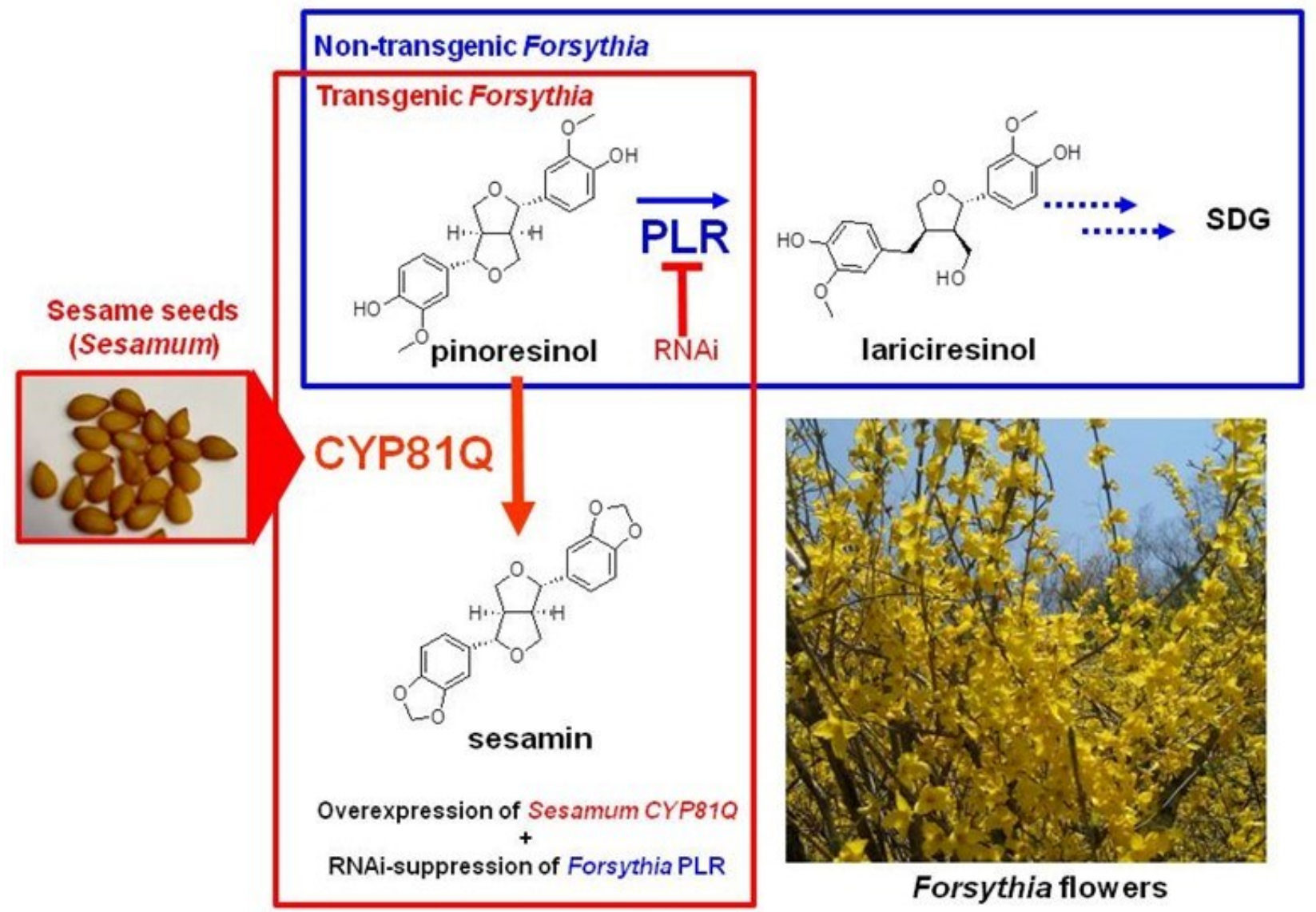

Figure 3. Metabolic Engineering of Forsythia Suspension Cell Cultures. The Transgenic Forsythia Suspension Cell Culture, CPi-Fk cells, Acquired the Ability to Produce Sesamin by Stable Transfection of PLR-RNAi and the Sesamum CYP81Q1 Gene.

RNAi-based metabolic engineering was attempted in various Linum species to produce endogenous lignans. Hairy roots of $L$. perenne transiently transfected with PLR-RNAi reduced the production of the major endogenous lignan, justicidin B, to $25 \%$, compared with the untreated hairy roots [58]. Likewise, transient transfection of $L$. corymbulosum hairy roots with PLR-RNAi resulted in a marked reduction of hinokinin [59]. Combined with the justicidin B and hinokinin biosynthetic pathways, in which PLR converts pinoresinol into secoisolariciresinol (Figure 2), these findings indicate that PLR-directed conversion of pinoresinol into secoisolariciresinol is a rate-limiting step in justicidin B and hinokinin biosynthesis, at least in the hairy roots of L. perenne and L. corymbulosum, respectively. Identification and genetic manipulation of justicidin $\mathrm{B}$ and hinokinin synthase will contribute a great deal to the establishment of procedures for the direct metabolic engineering of these lignans. Seed coats of PLRRNAi-transgenic plants of $L$. usitatissimum showed the high accumulation of pinoresinol diglucoside and loss of SDG [84]. Intriguingly, these PLR-RNAi-transgenic plants produced the 8-5' linked neolignans, dehydrodiconifnyl alcohol and dihydro- dehydrodiconifnyl alcohol, neither of which was detected in the wildtype plants [84]. Taken together, these findings reinforce the potential of Forsythia and Linum transgenic or transiently gene-transfected cells and plants as the metabolic engineering-based platforms for on-demand production of both endogenous and exogenous lignans. The draft genome and transcriptome of Linum usitatissimum [77-79] will accelerate the identification of the enzymes involved in the biosynthesis of Linum lignans, leading to the efficient lignan production using gene-modified plant sources. 
Two factors should be considered in constructing gene-modified plant platforms for lignan production, the type of host and the use of transgenic or transiently transfected hosts. Host types can include plants, organs, and cell cultures. For example, although the amount of sesamin produced by CPi-Fk cells is 100to 200-fold lower than that by native sesame seeds, CPi-Fk-based lignan metabolic engineering has several advantages. CPi-Fk cells proliferate 10-fold in two weeks in standard culture medium [63], and can be cultivated at all times and locations, whereas sesame seeds are cultivated in limited regions only once a year. Moreover, the conditions used in the culturing CPi-Fk cells, including temperature, light wavelength and intensity, and medium components, can be altered to optimize sesamin production. Forsythia plants have much greater biomass, with higher amount of lignans, than suspension cell cultures, and these plants can grow and propagate from small explants without flowering or seed formation. However, efficient generation of transgenic Forsythia plants still requires further basic research due to the markedly low transformation efficiency by any known gene transfection methods and deviation among Forsythia species [85-87]. In contrast, the generation of both stable (namely transgenic) and transient transfectants of Linum species are well established, and thus, the amounts of precursors or intermediates of targeted lignans are major determinants for the employment of cell cultures, organ cultures, or plants as host platforms. Additionally, gene-modified host plants may fail to normally grow or to produce lignans of interest due to pytotoxicity of lignans, although the underlying molecular mechanisms have not fully been elucidated [3,11,12,18-20,22]. Therefore, generation of lignan-producing plants using multiple plant species is occasionally required.

The second factor involves construction of either transgenic or transiently transfected hosts. Transgenic plants and cell cultures, once generated, are sustainably used for lignan production and readily up-scaled, whereas generation of transgenic plants, in particular non-model plants, may consume time and costs. Moreover, cultivation of transgenic plants in general requires a closed facility for gene-stably modified plants. Transiently transfected plants require repeated transfections, and transient transfection of multiple genes is likely to reduce the transfection efficiency. In addition, massive transient transfection remains to be fully developed [88]. Further research on lignan metabolic engineering, using transgenic or transiently gene-transfected plants, organ cultures, and cell cultures, is expected to lead to the establishment of both universal and molecular species-specific strategies for gene-regulated metabolic engineering of lignan biosynthesis pathways.

\subsection{Light Irradiation}

Biosynthesis of several secondary metabolites, including anthocyanin, carotenoid, and shikonin, is affected by wavelength [89-92]. Light irradiation has also been shown to improve the production of both endogenous and exogenous lignans by CPi-Fk cells. Irradiation of CPi-Fk cells for two weeks with white fluorescent, blue LED, and red LED light increased sesamin production 2.3-, 2.7-, and 1.6-fold, respectively, compared with cells cultured in the dark [93]. Likewise, irradiation of CPi-Fk cells increased pinoresinol (aglycone and glucoside) production 1.5 to 3.0-fold [93]. Intriguingly, expression of the pinoresinol-glucosylating enzyme UGT71A18 was also downregulated in CPi-Fk cells under blue LED or red LED light, leading to the increase of sesamin production [93], given that pinoresinol glucoside is not metabolized into sesamin by CYP81Q1 [12,75]. In Linum species, suspension of L. album cells produced two-fold more PTOX under red light than those in the dark [94]. Compared 
with white fluorescent light, irradiation of $S$. indicum leaves 3-5 weeks after sowing with blue LED light increased sesamin content 2.0-fold, whereas irradiation with red LED light reduced sesamin content twofold $[9,95]$. Although the underlying molecular mechanism has yet to be clarified, light irradiation can also improve lignan productivity by both cell cultures and plants.

\subsection{Elicitation}

Plants defense systems are triggered upon injury or infection via signaling by the phytohormones, methyl jasmonate (MeJA) and salicylic acid (SA), and treatment with elicitors, including fungi, their extracts and the glycan components, MeJA and SA, also mimic such activation. Moreover, lignans, at least in part, are believed to be involved in host defense systems $[12,18,96]$. In combination, elicitors are expected to enhance lignan biosynthesis [18,97]. As summarized in Table 1, the effects of various elicitors on lignan production have been examined in a wide variety of cell cultures and hairy roots of Forsythia, Juniperus, and Podophyllum (Table 1). MeJA and SA were found to increase the production of PTOX and the structurally related lignan production or the gene expression of lignan biosynthetic enzymes responsible for synthesis of conifenyl alcohol, phenylalanine ammonialyase (PAL), cinnamoylCoA reductase (CCR), and cinnammylalcohol dehydrogenasein (CAD) in cell suspension cultures of $L$. album [98,99], and L. nodiflorum [98], Podophyllum hexandrum [100] and callus of L. austriacum callus culture [101]. These phytohormones also increased the PTOX production or the relevant gene expression in hairy roots of L. tauricum [102]. Additionally, an increase in production of pinoresinol and matairesinol by MeJA was observed in Forsythia intermedia cell suspension culture [103]. Chitosan, chitin oligomers, and other glycans also enhanced PTOX production or gene expression of lignan biosynthetic enzymes in Juniperus chinensis callus culture [104], L. austriacum callus culture [101], and L. album cell suspension culture and hairy roots [105-107]. In particular, comparisons of chitin tetramer, pentamer, and hexamer and chitosan tetramer and pentamer showed that treatment of $L$. album hairy roots with chitosan hexamer for five days most potently enhanced PTOX and lariciresinol production, as well as upregulating the expression of $P A L, C C R, C A D$, and $P L R$ genes [107]. Overall, treatment with these elicitors resulted in 2- to 7-fold increases in PTOX synthesis and expression of genes encoding enzymes involved in the early steps of lignan biosynthesis in various plant cells and hairy roots.

Fungal co-culturing, extracts, and filtrate exhibited unique effects on the metabolic engineering of lignan production (Table 1). Botrytis cinerea, Phoma exigua and Fusarium oxysporum extracts triggered the accumulation of monolignols, and enhanced PAL activity and gene expression of $P A L$, $C C R$ and $C A D$ in L. usitatissimum cell suspension cultures [108]. Treatment of in L. album cell cultures with Fusarium graminearum extract for five days increased PTOX 7.0-fold and PAL, CCR, and CAD mRNAs $>10$-fold, compared with untreated cells, indicating that this extract is a more potent elicitor of PTOX production and PAL, CCR, and CAD expression than treatment with chitosan, chitin, or MeJA treatment for three days [105,106,109]. In contrast, Rhizopus stolonifer and Rhizoctonia solani extract stimulated 8.8-fold and 6.7-fold greater accumulation of lariciresinol, instead of PTOX, in L. album cell cultures after five-day treatment, as compared with untreated cells, and the highest (6.5-fold) PLR gene induction was observed in L. album cell cultures treated with Rhizopus stolonifer extract for two days [109]. Similar data were obtained in L. album hairy roots with the same fungal extracts [106] or L. album cell suspension culture with Fusarium graminearum culture filtrate [110], but the latter exhibited less lignan 
production. These studies revealed that fungal extract exhibited species-specific effects on the lignan biosynthesis pathways, although investigation of the molecular basis awaits further study. Examination of the regulation of gene expression has thus far been restricted to enzymes responsible for the upstream of lignan biosynthesis pathways, indicating that the effects of elicitors on the gene expression of the enzymes involved in the downstream of lignan biosynthesis such as SIRD and CYP719A23, and lignan glucosyltransferases (Figure 2) will lead to the identification of more effective elicitors for lignan production.

Table 1. List of Major Elicitors and Their Effects on Lignan Biosynthesis.

\begin{tabular}{|c|c|c|c|}
\hline Elicitor & Target & Effect & References \\
\hline $\begin{array}{l}\text { Chito-oligosaccharides } \\
(1 \mathrm{mg})\end{array}$ & $\begin{array}{l}\text { Juniperus chinensis } \\
\text { callus culture }\end{array}$ & Increased PTOX production & {$[104]$} \\
\hline $\begin{array}{l}\text { Methyl jasmonate } \\
(\text { MeJA) }(100 \mu \mathrm{M})\end{array}$ & $\begin{array}{l}\text { Forsythia intermedia } \\
\text { cell suspension culture }\end{array}$ & $\begin{array}{l}\text { Increased pinoresinol and } \\
\text { matairesinol production }\end{array}$ & [103] \\
\hline $\begin{array}{l}\text { Mannan }\left(0.1 \mathrm{mg} \mathrm{mL}^{-1}\right) \\
\beta-1,3 \text {-glucan } \\
\left(0.1 \mathrm{mg} \mathrm{mL}^{-1}\right) \\
\text { Ancymidol }\left(10^{-7} \mathrm{M}\right)\end{array}$ & $\begin{array}{l}\text { L. austriacum } \\
\text { callus culture }\end{array}$ & $\begin{array}{l}\text { Enhanced activity of tyrosine } \\
\text { ammonia-lyase (TAL), coumarate } \\
\text { 3-hydroxylase }(\mathrm{C} 3 \mathrm{H}), \\
\text { polyphenoloxidase (PPO) and PAL } \\
\text { Increased PTOX, 6-MPTOX, dPTOX, } \\
\alpha \text { - and } \beta \text {-peltatins production } \\
\text { Increaded PTOX and } \\
\alpha \text {-peltatins production } \\
\text { Increaded PTOX, 6-MPTOX, } \\
\text { dPTOX and } \alpha \text { - peltatins production }\end{array}$ & {$[101]$} \\
\hline $\begin{array}{l}\text { Indanoyl-isoleucine } \\
(5-100 \mu \mathrm{M}) \\
\text { Coronalon, }(10-50 \mu \mathrm{M}) \\
\operatorname{MeJA}(100 \mu \mathrm{M})\end{array}$ & $\begin{array}{l}\text { L. nodiflorum cell } \\
\text { suspension culture }\end{array}$ & $\begin{array}{l}\text { Increased deoxypodophyllotoxin } \\
\text { production } \\
\text { Enhanced activity of 6-hydroxylase } \\
\text { and } \beta \text {-peltatin 6-O-methyltransferas, } \\
\text { Increased 6-MPTOX and } \\
\text { 5'-d-6-MPTOX production }\end{array}$ & [97] \\
\hline MeJA $(100 \mu \mathrm{M})$ & $\begin{array}{l}\text { L. album cell } \\
\text { suspension culture }\end{array}$ & Increased PTOX production & [98] \\
\hline $\begin{array}{l}\text { Botrytis cinerea extract } \\
(3 \% \mathrm{v} / \mathrm{v}) \\
\text { Phoma exigua extract } \\
(3 \% \mathrm{v} / \mathrm{v}) \\
\text { Fusarium oxysporum } \\
\text { extract }(3 \% \mathrm{v} / \mathrm{v})\end{array}$ & $\begin{array}{l}\text { L. usitatissimum cell } \\
\text { suspension culture }\end{array}$ & $\begin{array}{l}\text { Rapid stimulation of the monolignol } \\
\text { pathway, enhanced PAL activity } \\
\text { and expression of genes } \\
\text { encoding PAL, CCR and CAD }\end{array}$ & [108] \\
\hline MeJA $(50-200 \mu \mathrm{M})$ & $\begin{array}{l}\text { L. tauricum hairy } \\
\text { root culture }\end{array}$ & $\begin{array}{l}\text { Increased 6MPTOX and } \\
\text { 4'-DM6MPTOX production }\end{array}$ & {$[102]$} \\
\hline $\begin{array}{l}\text { Salicylic acid (SA) } \\
(10 \mu \mathrm{M})\end{array}$ & $\begin{array}{l}\text { L. album cell } \\
\text { suspension culture }\end{array}$ & $\begin{array}{l}\text { Enhanced } P A L, C C R \text { and } \\
C A D \text { gene expression and } \\
\text { PTOX production }\end{array}$ & [99] \\
\hline
\end{tabular}


Table 1. Cont.

\begin{tabular}{|c|c|c|c|}
\hline Elicitor & Target & Effect & Refs \\
\hline $\begin{array}{l}\text { Chitin }\left(100 \mathrm{mg} \mathrm{l}^{-1}\right) \\
\text { Chitosan } \\
\left(100-200 \mathrm{mg} \mathrm{L}^{-1}\right) \\
\text { MeJA }(100-200 \mu \mathrm{M})\end{array}$ & $\begin{array}{l}\text { L. album cell } \\
\text { suspension culture }\end{array}$ & $\begin{array}{l}\text { Increased lariciresinol and/or } \\
\text { PTOX production }\end{array}$ & {$[105]$} \\
\hline $\begin{array}{l}\text { Fusarium graminearum } \\
\text { extract }(1 \% \mathrm{v} / \mathrm{v}) \\
\text { Sclerotinia sclerotiorum } \\
\text { extract }(1 \% \mathrm{v} / \mathrm{v}) \\
\text { Rhizopus stolonifer } \\
\text { extract }(1 \% \mathrm{v} / \mathrm{v}) \\
\text { Rhizoctonia solani } \\
\text { extract }(1 \% \mathrm{v} / \mathrm{v})\end{array}$ & $\begin{array}{l}\text { L. album cell } \\
\text { suspension culture }\end{array}$ & $\begin{array}{l}\text { Enhanced } P A L, C C R, C A D, \\
\text { and } P L R \text { gene expression } \\
\text { Increased PTOX and } \\
\text { lariciresinol production }\end{array}$ & {$[105,109]$} \\
\hline $\operatorname{MeJA}(10-100 \mu \mathrm{M})$ & $\begin{array}{l}\text { Podophyllum } \\
\text { hexandrum cell } \\
\text { suspension cultute }\end{array}$ & $\begin{array}{l}\text { Changes in cell proteome, } \\
\text { Increased PTOX production }\end{array}$ & [109] \\
\hline $\begin{array}{l}\text { Fusarium graminearum } \\
\text { extract }(1 \% \mathrm{v} / \mathrm{v}) \\
\text { Sclerotinia sclerotiorum } \\
\text { extract }(1 \% \mathrm{v} / \mathrm{v}) \\
\text { Trichoderma viride } \\
\text { extract }(1 \% \mathrm{v} / \mathrm{v}) \\
\text { Chitosan }\left(100 \mathrm{mg} \mathrm{l}^{-1}\right)\end{array}$ & $\begin{array}{l}\text { L. album hairy } \\
\text { root culture }\end{array}$ & $\begin{array}{l}\text { Enhanced } P A L, C C R, C A D \\
\text { and } P L R \text { gene expression, } \\
\text { Increased PTOX, 6MPTOX, } \\
\text { and lariciresinol production }\end{array}$ & {$[106]$} \\
\hline $\begin{array}{l}\text { Chitosan and chitin } \\
\text { oligomers }\left(100 \mathrm{mg} \mathrm{L}^{-1}\right)\end{array}$ & $\begin{array}{l}\text { L. album cell } \\
\text { suspension culture }\end{array}$ & $\begin{array}{l}\text { Enhanced } P A L, C C R, C A D \\
\text { and } P L R \text { gene expression, } \\
\text { Increased PTOX, 6MPTOX } \\
\text { and lariciresinol production }\end{array}$ & [107] \\
\hline $\begin{array}{l}\text { Fusarium graminearum } \\
\text { culture filtrate }(1 \% \mathrm{v} / \mathrm{v})\end{array}$ & $\begin{array}{l}\text { L. album cell } \\
\text { suspension culture }\end{array}$ & $\begin{array}{l}\text { Increased phenolic compound, } \\
\text { PTOX and lariciresinol production } \\
\text { Enhanced PAL activity, }\end{array}$ & [110] \\
\hline
\end{tabular}

\section{Conclusions}

There have been many recent advances in metabolic engineering for lignan production by plants, including: (i) the molecular characterization of novel genes encoding enzymes for biosynthesis pathways of dietary and medicinal lignans; (ii) the production of both endogenous and exogenous lignans by transient or stable transfection of lignan biosynthetic genes into cultured cells, tissues and plants; and (iii) the identification of exogenous stimuli such as light and elicitors that increase the production of lignans by cultured cells and plants. Taken together, combination of gene transfection, light, and elicitors is a promising strategy for further improvement of the lignan productivity; e.g., elicitation of CPi-Fk under blue or red LED light is expected to increase the amounts of sesamin. Moreover, bioinformatic analysis based on the aforementioned experimental data will lead to the systematic prediction of optimal lignan production strategy: hosts (cells, organ cultures, plants), light conditions, elicitor types, and transfection types, given that different optimal production of respective lignans is 
highly likely to occur under different conditions. For example, three Forsythia varieties, F. koreana, $F$. intermedia, and $F$. suspensa displayed differential growth and regeneration in a medium componentor selection marker antibiotics-dependent fashions [84], and Linum spp. showed genus-specific sensitivities to different elicitors (Table 1).

Public acceptance of dietary products derived from transgenic organisms is limited. Nevertheless, lignans produced by transgenic hosts are chemically identical to natural ones, and free from any recombinant genes or proteins. Thus, their public acceptance is expected to be more easily garnered than that of transgenic foods. Accordingly, more attention should be paid to the establishment of scaling-up and following industrialization of the lignan production systems [111-113]. Large-scale lignan production by transgenic plants requires a closed cultivation system to prevent contamination of the environment by transgenic plants. Recently, various closed plant factories have been emerging, which completely shut off a gene flow into the outer environment and enables the transgenic plants-based molecular breeding of genes or compounds of interest under optimal and sterile conditions [111-113]. Such advances in the metabolic engineering of lignan biosynthesis, combined with the aforementioned outcomes of a wide range of basic research, will surely pave the way for the conversion of conventional agricultural lignan production to innovative industrial lignan production.

\section{Acknowledgments}

This work was, in part, supported by the Plant Factory Project of the Ministry of Economy, Technology, and Industry of Japan.

\section{Author contributions}

Honoo Satake, Tomotsugu Koyama, Sedigheh Esmaeilzadeh Bahabadi, Erika Matsumoto, Eiichiro Ono, and Jun Murata wrote the manuscript.

\section{Conflicts of Interest}

The authors declare no conflict of interest.

\section{References}

1. Umezawa, T. Diversity in lignan biosynthesis. Phytochem. Rev. 2003, 2, 371-390.

2. Suzuki, S.; Umezawa, T. Biosynthesis of lignans and norlignans. J. Wood. Sci. 2007, 53, 273-284.

3. Macías, F.A.; López, A.; Varela, R.M.; Torres, A.; Molinillo, J.M.G. Bioactive lignans from a cultivar of Helianthus annuus. J. Agric. Food Chem. 2004, 52, 6443-6447.

4. Lee, J.; Choe, E. Extraction of lignan compounds from roasted sesame oil and their effects on the autoxidation of methyl linoleate. J. Food Sci. 2006, 71, C430-C436.

5. Guo, H.; Liu, A-H.; Ye, M.; Yang, M.; Guo, D.-A. Characterization of phenolic compounds in the fruits of Forsythia suspense by high-performance liquid chromatography coupled with electrospray ionization tandem mass spectrometry. Rapid Commun. Mass Spectrom. 2007, 21, $715-729$. 
6. Peñalvo, J.L.; Adlercreutz, H.; Uehara, M.; Ristimaki, A.; Watanabe, S. Lignan content of selected foods from Japan. J. Agric. Food Chem. 2008, 56, 401-409.

7. Piao, X.-L.; Jang, M.-H.; Cui, J.; Piao, X. Lignans from the fruits of Forsythia suspensa. Bioorg. Med. Chem. Lett. 2008, 18, 1980-1984.

8. Hata, N.; Hayashi, Y.; Okazawa, A.; Ono, E.; Satake, H.; Kobayashi, A. Comparison of sesamin contents and CYP81Q1 gene expressions in aboveground vegetative organs between two Japanese sesame (Sesamum indicum L.) varieties differing in seed sesamin contents. Plant Sci. 2010, 178, $510-516$.

9. Hata, N.; Hayashi, Y.; Ono, E.; Satake, H.; Kobayashi, A.; Muranaka, T.; Okazawa, A. Differences in plant growth and leaf sesamin content of the lignan-rich sesame variety "Gomazou" under continuous light of different wavelengths. Plant Biotechnol. 2013, 30, 1-8.

10. Okazawa, A.; Hori, K.; Okumura, R.; Izumi, Y.; Hata, N.; Bamba, T.; Fukusaki, E.; Ono, E.; Satake, H.; Kobayashi, A. Simultaneous quantification of lignans in Arabidopsis thaliana by highly sensitive capillary liquid chromatography-electrospray ionization-ion trap mass spectrometry. Plant Biotechnol. 2011, 28, 287-293.

11. Schmidt, T.J.; Klaes, M.; Sendker, J. Lignans in seeds of Linum species. Phytochemistry 2012, 82, 89-99.

12. Satake, H.; Ono, E.; Murata, J. Recent advances in metabolic engineering of lignan biosynthesis pathways for the production of transgenic plant-based foods and supplements. J. Agric. Food Chem. 2013, 61, 11721-11729.

13. Chaurasia, O.P.; Ballabh, B.; Tayade, A.; Kumar, R.; Kumar, G.P.; Singh, S.B. Podophyllum L.: An endangered and anticancerous medicinal plant-An overview. Indian J. Tradit. Know. 2012, $11,234-241$.

14. Ionkova, I. Biotechnological approaches for the production of lignans. Phcog. Rev. 2007, 1, 57-68.

15. Ionkova, I.; Antonova, I.; Momekov, G.; Fuss, E. Production of podophyllotoxin in Linum linearifolium in vitro cultures. Pharmacogn. Mag. 2010, 6, 180-185.

16. Ionkova, I. Anticancer lignans-from discovery to biotechnology. Mini. Rev. Med. Chem. 2011, $11,843-856$.

17. Lata, H.; Mizuno, C.S.; Moraes, R.M. The role of biotechnology in the production of the anticancer compound podophyllotoxin. Methods. Mol. Biol. 2009, 547, 387-402.

18. Malik, S.; Biba, O.; Grúz, J.; Arroo, R.R.J.; Strnad, M. Biotechnological approaches for producing aryltetralin lignans from Linum species. Phytochem. Rev. 2014, 13, 893-913.

19. Oliva, A.; Moraes, R.A.; Watson, S.B.; Duke, S.O.; Dayan, F.E. Aryltertralin lignans inhibit plant growth by affecting formation of mitotic microtubular organizing centers. Pestic. Biochem. Phys. 2002, 72, 45-54.

20. Harmatha, J.; Dinan, L. Biological activities of lignans and stilbenoids associated with plant-insect chemical interaction. Phytochem. Rev. 2003, 2, 321-330.

21. Schroeder, F.C.; del Campo, M.L.; Grant, J.B.; Weibel, D.B.; Smedley, S.R.; Bolton, K.L.; Meinwald, J.; Eisner, T. Pinoresinol: A lignol of plant origin serving for defense in a caterpillar. Proc. Natl. Acad. Sci. USA 2006, 103, 15497-15501. 
22. Cutillo, F.; D'Abrosca, B.; DellaGreca, M.; Fiorentino, A.; Zarrelli, A. Lignans and neolignans from Brassica fruticulosa: Effects on seed germination and plant growth. J. Agric. Food Chem. 2003, 51, 6165-6172.

23. Nishiwaki, H.; Kumamoto, M.; Shuto, Y.; Yamauchi, S. Stereoselective syntheses of all stereoisomers of lariciresinol and their plant growth inhibitory activities. J. Agric. Food. Chem. 2011, 59, 13089-13095.

24. Carillo, P.; Cozzolino, C.; D’Abrosca, B.; Nacca, F.; DellaGreca, M.; Fiorentio, A.; Fuggi, A. Effects of the allelochemicals dihydrodiconiferylalcohol and lariciresinol on metabolism of Lactuca sativa. Open Bioact. Compd .J. 2010, 3, 18-24.

25. Heinonen, S.; Nurmi, T.; Liukkonen, K.; Poutanen, K.; Wähälä, K.; Deyama, T.; Nishibe, S.; Adlercreutz, H. In vitro metabolism of plant lignans: New precursors of mammalian lignans enterolactone and enterodiol. J. Agric. Food Chem. 2001, 49, 3178-3186.

26. Lampe, J.W.; Atkinson, C.; Hullar, M.A. Assessing exposure to lignans and their metabolites in humans. J. AOAC Int. 2006, 89, 1174-1181.

27. Liu, Z.; Saarinen, N.M.; Thompson, L.U. Sesamin is one of the major precursors of mammalian lignans in sesame seed (Sesamum indicum) as observed in vitro and in rats. J. Nutr. 2006, 136, 906-912.

28. Mueller, S.O.; Simon, S.; Chae, K.; Metzler, M.; Korach, K.S. Phytoestrogens and their human metabolites show distinct agonistic and antagonistic properties on estrogen receptor alpha $(\mathrm{ER} \alpha)$ and ER $\beta$ in human cells. Toxicol. Sci. 2004, 80, 14-25.

29. Penttinen, P.; Jaehrling, J.; Damdimopoulos, A.E.; Inzunza, J.; Lemmen, J.G.; van der Saag, P.; Pettersson, K.; Gauglitz, G.; Mäkelä, S.; Pongratz, I. Diet-derived polyphenol metabolite enterolactone is a tissue-specific estrogen receptor activator. Endocrinology 2007, 148, 4875-4886.

30. During, A.; Debouche, C.; Raas, T.; Larondelle, Y. Among plant lignans, pinoresinol has the strongest antiinflammatory properties in human intestinal Caco-2 cells. J. Nutr. 2012, 142, 1798-1805.

31. Adlercreutz, H. Lignans and human health. Crit. Rev. Cl. Lab. Sci. 2007, 44, 483-525.

32. Bergman Jungeström, M.; Thompson, L.U.; Dabrosin, C. Flaxseed and its lignans inhibit estradiol-induced growth, angiogenesis, and secretion of vascular endothelial growth factor in human breast cancer xenografts in vivo. Clin. Cancer. Res. 2007, 13, 1061-1067.

33. Power, K.A.; Saarinen, N.M.; Chen, J.-M.; Thompson, L.U. Mammalian lignans enterolactone and enterodiol, alone and in combination with the isoflavone genistein, do not promote the growth of MCF-7 xenografts in ovariectomized athymic nude mice. Int. J. Cancer 2006, 118, 1316-1320.

34. Mense, S.M.; Hei, T.K.; Ganju, R.K.; Bhat, H.K. Phytoestrogens and breast cancer prevention: Possible mechanisms of action. Environ. Health Persp. 2008, 116, 426-433.

35. Saarinen, N.M.; Wärri, A.; Dings, R.P.M.; Airio, M.; Smeds, A.I.; Mäkelä, S. Dietary lariciresinol attenuates mammary tumor growth and reduces blood vessel density in human MCF-7 breast cancer xenografts and carcinogen-induced mammary tumors in rats. Int. J. Cancer 2008, 123, 1196-1204.

36. Adolphe, J.L.; Whiting, S.J.; Juurlink, B.H.J.; Thorpe, L.U.; Alcorn, J. Health effects with consumption of the flax lignan secoisolariciresinol diglucoside. Br. J. Nutr. 2010, 103, 929-938. 
37. Barre, D.E.; Mizier-Barre, K.A.; Stelmach, E.; Hobson, J.; Griscti, O.; Rudiuk, A.; Muthuthevar, D. Flaxseed lignan complex administration in older human type 2 diabetics manages central obesity and prothrombosis-an invitation to further investigation into polypharmacy reduction. $J$. Nutr. Metab. 2012, 585170.

38. Hano, C.; Renouard, S.; Molinié, R.; Corbin, C.; Barakzoy, E.; Doussot, J.; Lamblin, F.; Lainé, E. Flaxseed (Linum usitatissimum L.) extract as well as $(+)$-secoisolariciresinol diglucoside and its mammalian derivatives are potent inhibitors of $\alpha$-amylase activity. Bioorg. Med. Chem. Lett. 2013, 23, 3007-3012.

39. Sirato-Yasumoto, S.; Katsuta, M.; Okuyama, Y.; Takahashi, Y.; Ide, T. Effect of sesame seeds rich in sesamin and sesamolin on fatty acid oxidation in rat liver. J. Agric. Food Chem. 2001, 49, 2647-2651.

40. Nakano, D.; Itoh, C.; Takaoka, M.; Kiso, Y.; Tanaka, T.; Matsumura, Y. Antihypertensive effect of sesamin. IV. Inhibition of vascular superoxide production by sesamin. Biol. Pharm. Bull. 2002, $25,1247-1249$.

41. Nakai, M.; Harada, M.; Nakahara, K.; Akimoto, K.; Shibata, H.; Miki, W.; Kiso, Y. Novel antioxidative metabolites in rat liver with ingested sesamin. J. Agric. Food. Chem. 2003, 51, 1666-1670.

42. Akimoto, K.; Kitagawa, Y.; Akamatsu, T.; Hirose, N.; Sugano, M.; Shimizu, S.; Yamada, H. Protective effects of sesamin against liver damage caused by alcohol or carbon tetrachloride in rodents. Ann. Nutr. Metab. 1993, 37, 218-224.

43. Tada, M.; Ono, Y.; Nakai, M.; Harada, M.; Shibata, H.; Kiso, Y.; Ogata, T. Evaluation of antioxidative effects of sesamin on the in vivo hepatic reducing abilities by a radiofrequency ESR method. Anal. Sci. 2013, 29, 89-94.

44. Liu, C.-M.; Zheng, G.-H.; Ming, Q.-L.; Cheng, C.; Sun, J.M. Sesamin protects mouse liver against nickel-induced oxidative DNA damage and apoptosis by the PI3K/Akt pathway. J. Agri. Food Chem. 2013, 61, 1146-1154.

45. Saarinen, N.M.; Wärri, A.; Airio, M.; Smeds, A.; Mäkelä, S. Role of dietary lignans in the reduction of breast cancer risk. Mol. Nutr. Food Res. 2007, 51, 857-866.

46. Velentzis, L.S.; Cantwell, M.M.; Cardwell, C.; Keshtgar, M.R.; Leathem, A.J.; Woodside, J.V. Lignans and breast cancer risk in pre- and post-menopausal women: Meta-analyses of observational studies. Br. J. Cancer 2009, 100, 1492-1498.

47. Velentzis, L.S.; Keshtgar, M.R.; Woodside, J.V.; Leathem, A.J.; Titcomb, A.; Perkins, K.A.; Mazurowska, M.; Anderson, V.; Wardell, K.; Cantwell, M.M. Significant changes in dietary intake and supplement use after breast cancer diagnosis in a UK multicentre study. Breast Cancer Res. Treat. 2011, 128, 473-482.

48. Buck, K.; Zaineddin, A.K.; Vrieling, A.; Linseisen, J.; Chang-Claude, J. Meta-analyses of lignans and enterolignans in relation to breast cancer risk. Am. J. Clin. Nutr. 2010, 92, 141-153.

49. Buck, K.; Zaineddin, A.K.; Vrieling, A.; Heinz, J.; Linseisen, J.; Flesch-Janys, D.; Chang-Claude, J. Estimated enterolignans, lignan-rich foods, and fibre in relation to survival after postmenopausal breast cancer. Br. J. Cancer 2011, 105, 1151-1157. 
50. Zaineddin, A.K.; Buck, K.; Vrieling, A.; Heinz, J.; Flesch-Janys, D.; Linseisen, J.; Chang-Claude, J. The association between dietary lignans, phytoestrogen-rich foods, and fiber intake and postmenopausal breast cancer risk: A German case-control study. Nutr. Cancer 2012, 64, 652-665.

51. Buck, K.; Vrieling, A.; Zaineddin, A.K.; Becker, S.; Hüsing, A.; Kaaks, R.; Linseisen, J.; Flesch-Janys, D.; Chang-Claude, J. Serum enterolactone and prognosis of postmenopausal breast cancer. J. Clin. Oncol. 2011, 29, 3730-3738.

52. Chen, J.M.; Saggar, J.K.; Corey, P.; Thompson, L.U. Flaxseed and pure secoisolariciresinol diglucoside, but not flaxseed hull, reduce human breast tumor growth (MCF-7) in athymic mice. J. Nutr. 2009, 139, 2061-2066.

53. Truan, J.S.; Chen, J.M.; Thompson, L.U. Comparative effects of sesame seed lignan and flaxseed lignan in reducing the growth of human breast tumors (MCF-7) at high levels of circulating estrogen in athymic mice. Nutr. Cancer. 2012, 64, 65-71.

54. Yousefzadi, M.; Sharifi, M.; Behmanesh, M.; Moyano, E.; Bonfill, M.; Cusido, R.M.; Palazon, J. Podophyllotoxin: Current approaches to its biotechnological production and future challenges. Eng. Life Sci. 2010, 10, 281-292.

55. Davin, L.B.; Lewis, N.G. A historical perspective on lignan biosynthesis: Monolignol, allylphenol and hydroxycinnamic acid coupling and downstream metabolism. Phytochem. Rev. 2003, 2, 257-288.

56. Dinkova-Kostova, A.T.; Gang, D.R.; Davin, L.B.; Bedgar, D.L.; Chu, A.; Lewis, N.G. (+)-pinoresinol/(+)-lariciresinol reductase from Forsythia intermedia. J. Biol. Chem. 1996, 271, 29473-29482.

57. Gang, D.R.; Kasahara, H.; Xia, Z.-Q.; Vander-Mijnsbrugge, K.; Bauw, G.; Boerjan, W.; van Montagu, M.; Davin, L.B.; Lewis, N.G. Evolution of plant defense mechanisms. Relationships of phenylcoumaran benzylic ether reductases to pinoresinol-lariciresinol and isoflavone reductases. J. Biol. Chem. 1999, 274, 7516-7527.

58. Hemmati, S.; Schmidt, T.J.; Fuss, E. (+)-pinoresinol/(-)-lariciresinol reductase from Linum perenne Himmelszelt involved in the biosynthesis of justicidin B. FEBS Lett. 2007, 581, 603-610.

59. Bayindir, Ü.; Alfermann, A.W.; Fuss, E. Hinokinin Biosynthesis in Linum corymbulosum Reichenb. Plant J. 2008, 55, 810-820.

60. Nakatsubo, T.; Mizutani, M.; Suzuki, S.; Hattori, T.; Umezawa, T. Characterization of Arabidopsis thaliana pinoresinol reductase, a new type of enzyme involved in lignan biosynthesis. J. Biol. Chem. 2008, 283, 15550-15557.

61. Wankhede, D.P.; Biswas, D.K.; Rajkumar, S.; Sinha, A.K. Expressed sequence tags and molecular cloning and characterization of gene encoding pinoresinol/lariciresinol reductase from Podophyllum hexandrum. Protoplasma 2013, 250, 1239-1249.

62. Ono, E.; Kim, H.-J.; Murata, J.; Morimoto, K.; Okazawa, A.; Kobayashi, A.; Umezawa, T.; Satake, H. Molecular and functional characterization of novel furofuran-class lignan glucosyltransferases from Forsythia. Plant Biotechnol. 2010, 27, 317-324.

63. Kim, H.-J.; Ono, E.; Morimoto, K.; Yamagaki, T.; Okazawa, A.; Kobayashi, A.; Satake, H. Metabolic engineering of lignan biosynthesis in Forsythia cell culture. Plant Cell Physiol. 2009, 50, 2200-2209. 
64. Morimoto, K.; Satake, H. Seasonal alteration in amounts of lignans and their glucosides and gene expression of the relevant biosynthetic enzymes in the Forsythia suspense leaf. Biol. Pharm. Bull. 2013, 36, 1519-1523.

65. Okazawa, A.; Kusunose, T.; Ono, E.; Kim, H.-J.; Satake, H.; Shimizu, B.; Mizutani, M.; Seki, H.; Muranaka, T. Glucosyltransferase activity of Arabidopsis UGT71C1 towards pinoresinol and lariciresinol. Plant Biotechnol. 2014, doi:10.5511/plantbiotechnology.14.0910a.

66. Xia, Z-Q.; Costa, M. A.; Pélissier, H.C.; Davin, L.B.; Lewis, N.G. Secoisolariciresinol dehydrogenase purification, cloning, and functional expression. J. Biol. Chem. 2001, 276, 12614-12623.

67. Ghose, K.; Selvaraj, K.; McCallum, J.; Kirby, C.W.; Sweeney-Nixon, M.; Cloutier, S.J.; Deyholos, M.; Datla, R.; Fofana, B. Identification and functional characterization of a flax UDP-glycosyltransferase glucosylating secoisolariciresinol (SECO) into secoisolariciresinol monoglucoside (SMG) and diglucoside (SDG). BMC Plant. Biol. 2014, doi:10.1186/1471-222914-82.

68. Umezawa, T.; Ragamustari, S.K.; Nakatsubo, T.; Wada, S.; Li, L.; Yamamura, M.; Sakakibara, N.; Hattori, T.; Suzuki, S.; Chiang, V.L. A lignan $O$-methyltransferase catalyzing the regioselective methylation of matairesinol in Carthamus tinctorius. Plant Biotechnol. 2013, 30, 97-109.

69. Ragamustari, S.K.; Yamamura, M.; Ono, E.; Hattori, T.; Suzuki, S.; Suzuki, H.; Shibata, D.; Umezawa, T. Substrate-enantiomer selectivity of matairesinol $O$-methyltransferases. Plant Biotechnol. 2014, 31, 257-267.

70. Ragamustari, S.K.; Nakatsubo, T.; Hattori, T.; Ono, E.; Kitamura, Y.; Suzuki, S.; Yamamura, M.; Umezawa, T. A novel $O$-methyltransferase involved in the first methylation step of yatein biosynthesis from matairesinol in Anthriscus sylvestris. Plant Biotechnol. 2013, 30, 375-384.

71. Marques, J.V.; Kim, K.-W.; Lee, C.; Costa, M.A.; May, G.D.; Crow, J.A.; Davin, L.B.; Lewis, N.G. Next generation sequencing in predicting gene function in podophyllotoxin biosynthesis. J. Biol. Chem. 2013, 288, 466-479.

72. Wang, L.; Yu, S.; Tong, C.; Zhao, Y.; Liu, Y.; Song, C.; Zhang, Y.; Zhang, X.; Wang, Y.; Hua, W.; et al. Genome sequencing of the high oil crop sesame provides insight into oil biosynthesis. Genome Biol. 2014, doi:10.1186/gb-2014-15-2-r39.

73. Wang, L.; Han, X.; Zhang, Y.; Li, D.; Wei, X.; Ding, X.; Zhang, X. Deep resequencing reveals allelic variation in Sesamum indicum. BMC Plant Biol. 2014, doi:10.1186/s12870-014-0225-3.

74. Wu, K.; Yang, M.; Liu, H.; Tao, Y.; Mei, J.; Zhao, Y. Genetic analysis and molecular characterization of Chinese sesame (Sesamum indicum L.) cultivars using insertion-deletion (InDel) and simple sequence repeat (SSR) markers. BMC Genet. 2014, doi:10.1186/1471-2156-15-35.

75. Ono, E.; Nakai, M.; Fukui, Y.; Tomimori, N.; Fukuchi-Mizutani, M.; Saito, M.; Satake, H.; Tanaka, T.; Katsuta, M.; Umezawa, T.; Tanaka, Y. Formation of two methylenedioxy bridges by a Sesamum CYP81Q protein yielding a furofuran lignan, (+)-sesamin. Proc. Natl. Acad. Sci. USA 2006, 103, 10116-10121.

76. Noguchi, A.; Fukui, Y.; Iuchi-Okada, A.; Kakutani, S.; Satake, H.; Iwashita, T.; Nakao, M.; Umezawa, T.; Ono, E. Sequential glucosylation of a furofuran lignan, (+)-sesaminol, by Sesamum indicum UGT71A9 and UGT94D1. Plant J. 2008, 54, 415-427. 
77. Wang, Z.; Hobson, N.; Galindo, L.; Zhu, S.; Shi, D.; McDill, J.; Yang, L.; Hawkins, S.; Neutelings, G.; Datla, R.; et al. The genome of flax (Linum usitatissimum) assembled de novo from short shotgun sequence reads. Plant J. 2012, 72, 461-473.

78. Barvkar, V.T.; Pardeshi, V.C.; Kale, S.M.; Kadoo, N.Y.; Gupta, V.S. Phylogenomic analysis of UDP glycosyltransferase 1 multigene family in Linum usitatissimum identified genes with varied expression patterns. BMC Genomics 2012, doi:10.1186/1471-2164-13-175.

79. Babu, P.R.; Rao, K.V.; Reddy, V.D. Structural organization and classification of cytochrome P450 genes in flax (Linum usitatissimum L.). Gene 2013, 513, 156-162.

80. Bhattacharyya, D.; Sinha, R.; Hazra, S.; Datta, R.; Chattopadhyay, S. De novo transcriptome analysis using 454 pyrosequencing of the Himalayan Mayapple, Podophyllum hexandrum. BMC Genomics 2013, doi:10.1186/1471-2164-14-748.

81. Marques, J.V.; Dalisay, D.S.; Yang, H.; Lee, C.; Davin, L.B.; Lewis, N.G. A multi-omics strategy resolves the elusive nature of alkaloids in Podophyllum species. Mol. Biosyst. 2014, 10, 2838-2849.

82. Eyberger, A.L.; Dondapati, R.; Porter, J.R. Endophyte fungal isolates from Podophyllum peltatum produce podophyllotoxin. J. Nat. Prod. 2006, 69, 1121-1124.

83. Schmitt, J.; Petersen, M. Pinoresinol and matairesinol accumulation in a Forsythia $\times$ intermedia cell suspension culture. Plant Cell Tiss. Org. 2002, 68, 91-98.

84. Renouard, S.; Tribalatc, M.-A.; Lamblin, F.; Mongelard, G.; Fliniaux, O.; Corbin, C.; Marosevic, D.; Pilard, S.; Demailly, H.; Gutierrez, L.; et al. RNAi-mediated pinoresinol lariciresinol reductase gene silencing in flax (Linum usitatissimum L.) seed coat: Consequences on lignans and neolignans accumulation. J. Plant Physiol. 2014, 171, 1372-1377.

85. Morimoto, K.; Ono, E.; Kim, H.-J.; Okazawa, A.; Kobayashi, A.; Satake, H. The construction of transgenic Forsythia plants: Comparative study of three Forsythia species. Plant Biotechnol. 2011, 28, 273-280.

86. Rosati, C.; Cadic, A.; Renou, J.-P.; Duron, M. Regeneration and Agrobacterium-mediated transformation of Forsythia x intermedia "Spring Glowly". Plant Cell Rep. 1996, 16, 114-117.

87. Rosati, C.; Simoneau, P.; Treutter, D.; Poupard, P.; Cadot, Y.; Cadic, A.; Duron, M. Engineering of flower color in forsythia by expression of two independently-transformed dihydroflavonol 4-reductase and anthocyanidin synthase genes of flavonoid pathway. Mol. Breeding 2003, 12, 197-208.

88. Chen, Q.; Lai, H.; Hurtado, J.; Stahnke, J.; Leuzinger, K.; Dent, M. Agroinfiltration as an Effective and scalable strategy of gene delivery for production of pharmaceutical proteins. Adv. Tech. Biol. Med. 2013, doi:10.4172/atbm.1000103.

89. Jackson, J.A.; Fuglevand, G.; Brown, B.A.; Shaw, M.J.; Jenkins, G.I. Isolation of Arabidopsis mutants altered in the light-regulation of chalcone synthase gene expression using a transgenic screening approach. Plant J. 1995, 8, 369-380.

90. Bharti, A.K.; Khurana, J.P. Mutants of Arabidopsis as tools to understand the regulation of phenylpropanoid pathway and UVB protection mechanisms. Photochem. Photobiol. 1997, 65, $765-776$. 
91. Von Lintig, J.; Welsch, R.; Bonk, M.; Giuliano, G.; Batschauer, A.; Kleinig, H. Light-dependent regulation of carotenoid biosynthesis occurs at the level of phytoene synthase expression and is mediated by phytochrome in Sinapis alba and Arabidopsis thaliana seedlings. Plant J. 1997, 12, 625-634.

92. Yazaki, K.; Matsuoka, H.; Ujihara, T.; Sato, F. Shikonin biosynthesis in Lithospermum erythrorhizon: Light-induced negative regulation of secondary metabolism. Plant Biotechnol. 1999, 16, 335-342.

93. Morimoto, K.; Kim, H.-J.; Ono, E.; Kobayashi, A.; Okazawa, A.; Satake, H. Effects of light on production of endogenous and exogenous lignans by Forsythia koreana wildtype and transgenic cells. Plant Biotechnol. 2011, 28, 331-337.

94. Yousefzadi, M.; Sharifi, M.; Behmanesh, M.; Ghasempour, A.; Moyano, E.; Palazon, J. The effect of light on gene expression and podophyllotoxin biosynthesis in Linum album cell culture. Plant Physiol. Biochem. 2012, 56, 41-56.

95. Hata, N.; Hayashi, Y.; Okazawa, A.; Ono, E.; Satake, H.; Kobayashi, A. Effect of photoperiod on growth of the plants, and sesamin content and CYP81Q1 gene expression in the leaves of sesame (Sesamum indicum L.). Environ. Exp. Bot. 2012, 75, 212-219.

96. Zhao, J.; Davis, L.C.; Verpoorte, R. Elicitor signal transduction leading to production of plant secondary metabolites. Biotechnol. Adv. 2005, 23, 283-333.

97. Berim, A.; Spring, O.; Conrad, J.; Maitrejean, M.; Boland, W.; Petersen, M. Enhancement of lignan biosynthesis in suspension cultures of Linum nodiflorum by coronalon, indanoyl-isoleucine and methyl jasmonate. Planta 2005, 222, 769-776.

98. Van Fürden, B.; Humburg, A.; Fuss, E. Influence of methyl jasmonate on podophyllotoxin and 6-methoxypodophyllotoxin accumulation in Linum album cell suspension cultures. Plant Cell Rep. 2005, 24, 312-317.

99. Yousefzadi, M.; Sharifi, M.; Behmanesh, M.; Ghasempour, A.; Moyano, E.; Palazon, J. Salicylic acid improves podophyllotoxin production in cell cultures of Linum album by increasing the expression of genes related with its biosynthesis. Biotechnol. Lett. 2010, 32, 1739-1743.

100. Bhattacharyya, D.; Sinha, R.; Ghanta, S.; Chakraborty, A.; Hazra.; S.; Chattopadhyay, S. Proteins differentially expressed in elicited cell suspension culture of Podophyllum hexandrum with enhanced podophyllotoxin content. Proteome Sci. 2012, doi:10.1186/1477-5956-10-34.

101. Vardapetyan, H.R.; Kirakosyan, A.B.; Oganesyan, A.A.; Penesyan, A.R.; Alfermann, W.A. Effect of various elicitors on lignan biosynthesis in callus cultures of Linum austriacum. Russ. J. Plant Physl. 2003, 50, 297-300.

102. Ionkova, I. Effect of methyl jasmonate on production of ariltetralin lignans in hairy root cultures of Linum tauricum. Pharmacogn. Res. 2009, 1, 102-105.

103. Schmitt, J.; Petersen, M. Influence of methyl jasmonate and coniferyl alcohol on pinoresinol and matairesinol accumulation in a Forsythia $\times$ intermedia suspension culture. Plant Cell Rep. 2002, 20, 885-890.

104. Muranaka, T.; Miyata, M.; Ito, K.; Tachibana, S. Production of podophyllotoxin in Juniperus chinensis callus cultures treated with oligosaccharides and a biogenetic precursor. Phytochemistry 1998, 49, 491-496. 
105. Bahabadi, S.E.; Sharifi, M.; Safaie, N.; Murata, J.; Yamagaki, T.; Satake, H. Increased lignan biosynthesis in the suspension cultures of Linum album by fungal extracts. Plant Biotechnol. Rep. 2011, 5, 367-373.

106. Bahabadi, S.E.; Sharifi, M.; Chashmi, N.A.; Murata, J.; Satake, H. Significant enhancement of lignans accumulation in hairy root cultures of Linum album using biotic elicitors. Acta. Physiol. Plant 2014, 36, 3325-3331.

107. Bahabadi, S.E.; Sharifi, M.; Murata, J.; Satake, H. The effect of chitosan and chitin oligomers on gene expression and lignan production in Linum album cell cultures. J. Med. Plant 2014, 13, 46-53.

108. Hano, C.; Addi, M.; Bensaddek, L.; Crônier, D.; Baltora-Rosset, S.; Doussot, J.; Maury, S.; Mesnard, B.; Chabbert, B.; Hawkins, S.; Lainé, E.; Lamblin, F. Differential accumulation of monolignol-drived compounds in elicited flax (Linum usitatissimum) cell suspension cultures. Planta 2006, 223, 975-989.

109. Bahabadi, S.E.; Sharifi, M.; Behmanesh, M.; Safaie, N.; Murata, J.; Araki, R.; Yamagaki, T.; Satake, H. Time-course changes in fungal elicitor-induced lignan synthesis and expression of the relevant genes in cell cultures of Linum album. J. Plant Physiol. 2012, 169, 487-491.

110. Tahsili, J.; Sharifi, M.; Safaie, N.; Bahabadi, S.E.; Behmanesh, M. Induction of lignans and phenolic compounds in cell culture of Linum album by culture filtrate of Fusarium graminearum. J. Plant Interact. 2014, 9, 412-417.

111. Chun, C.; Kozai, T. A closed transplant production system, a hybrid of scaled-up micropropagation system and plant factory. J Plant Biotechnol 2001, 3, 59-66.

112. Hirai, T.; Fukukawa, G.; Kakuta, H.; Fukuda, N.; Ezura, H. Production of recombinant miraculin using transgenic tomatoes in a closed cultivation system. J. Agric. Food Chem. 2010, 58, 6096-6101.

113. Kato, K.; Yoshida, R.; Kikuzaki, A.; Hirai, T.; Kuroda, H.; Hiwasa-Tanase, K.; Takane, K.; Ezura, H.; Mizoguchi, T. Molecular breeding of tomato lines for mass production of miraculin in a plant factory. J. Agric. Food Chem. 2010, 58, 9505-9510.

(C) 2015 by the authors; licensee MDPI, Basel, Switzerland. This article is an open access article distributed under the terms and conditions of the Creative Commons Attribution license (http://creativecommons.org/licenses/by/4.0/). 